\title{
Book review: Anthropomorphic images in rock art paintings and rock carvings
}

\author{
Ana Paula Motta \\ Centre for Rock Art Research and Management, The University of Western Australia, M257 35 Stirling \\ Highway, Crawley WA 6009, Australia. Email: ap_motta@hotmail.com
}

Anthropomorphic Images in Rock Art Paintings and Rock Carvings

edited by Terence Meaden and Herman Bender

Archaeopress, 2020, pp. 322. ISBN 978-178-969-357-7

https://www.archaeopress.com/archaeopressshop/public/displayProductDetail.asp?id=\{19B19455-

613A-41E7-968F-D99720CA62C2\}

In this ambitious book, Terence Meaden and Herman Bender explore the diverse manifestations of anthropomorphic figures in rock paintings and engravings globally. Anthropomorphic Images in Rock Art Painting and Rock Carvings is a compilation of papers originally presented at the International Federation of Rock Art Organisations (IFRAO) Conference, held in 2018 at Valcamonica Darfo Boario Terme (Italy). The book ventures into the recovery of meanings embedded in rock art repertoires, by juxtaposing formal and

Journal of Lithic Studies (2021) vol. 8, nr. 1, 3 p.

DOI: https://doi.org/10.2218/jls.6191

Published by the School of History, Classics and Archaeology, University of Edinburgh ISSN: 2055-0472. URL: http://journals.ed.ac.uk/lithicstudies/

Except where otherwise noted, this work is licensed under a CC BY 4.0 licence. 
informed approaches to rock art. The result is an extensive collection of articles (21 in total) that engage with the study of anthropomorphic - or human - representations across a diverse range of themes and organised into six geographic regions: Europe, Asia, Australia, Africa, North America, and South America.

The aim of this book is to provide an overview of the wide range of possible interpretations available for anthropomorphic motifs globally, into what can be deemed as one of the first attempts to bring together international researchers into a single volume. In the first part of the book, Meaden and Bender provide a short preface that groups the contributions into nine themes: Hieros gamos and fertility religions; expressive anthropomorphic imagery; rock art combining anthropomorphism with zoomorphism; Manitou in rock-art imagery in North America; childbirth; rock art indicative of death and afterlife expectations; ontology; general anthropomorphic imagery in Aboriginal Australia; and rock art in South America (Meaden \& Bender 2020: iii-viii). However, due to the broad range of topics explored in this volume, there is a lack of coherence between the contributions, which is perhaps partly due to the absence of an introductory chapter that contextualises the study of human figures in rock art. The introductory section could have reviewed instead the variety of methodological and theoretical perspectives advanced until present, while providing a framework for the volume at hand. Despite the editors' efforts to find a common ground between these 21 papers, the proposed classification in nine themes feels at times disjointed. This is, in part, because of the nature of the contributions: some areas have been subjected to over 30 years of study, whereas others are still in an early development phase and in need of a proper contextualisation and dating of the art. As a result, there is an imbalance among the contributions, some are skewed towards a more descriptive approach, while others present an in-depth interpretation of the rock art assemblages, delving into the role depictions play or played among past and present populations.

The chapters that follow explore a number of themes in anthropomorphic research in rock art studies: portrayals of fertility (Chapters 1, 2, 5, and 7), gender studies (Chapters 3, 9, 11, 13, and 15), general characterisation and description of human motifs found at particular areas and sites (Chapters 4, 5, 7, 11, 12, 19, 20, and 21), megalithic rock art and its links to archaeology of death and archaeoastronomy (Chapters 1, 6, 8, 15, and 16), embodiment and personhood approaches (Chapters 10, 13, and 14) and ethnography (Chapters 13, 14, 15, 16, 17, and 18).

Despite this volume being heavily populated by rock art contributions, there is a significant number of chapters that are dedicated to the study of stone features, mobiliary art, stone carvings, engraved stones, and sculptures (e.g., Chapters 1, 2, 6, 7, 8, 9, 15, 16, and 18). Chapters 1, 6, and 8 are dedicated to discussing stone circles and megaliths found in Europe, some of which contain engravings, and carved and sculpted stones that resemble human persons. These chapters do not discuss the qualities of the rocks, but rather focus on the symbolic function of these places. Similarly, Chapters 2, 7, 9, and 15 explore the role of stone features, such as engraved stones, mobiliary art, and sculptures in fertility ceremonies. Finally, Chapters 16 and 18 are concerned with mythology through the study of Manitou (or Spirit Stones) and thunderbird engravings.

Likewise, despite Meaden's and Bender's ambitious effort to collect contributions from all over the globe, it also becomes apparent that some research areas are overrepresented, while others are underrepresented. For example, articles engaging with European and North American rock art are among the most predominant ones. This comes as no surprise if we consider that this edited volume is the result of a conference held in Italy; however, it is worth highlighting that this imbalance can also be translated into a lack of opportunities to present and publish in international contexts for those coming from the global South. Similarly, despite the editors' well-intentioned attempt to include papers from six geographic regions, 
there is a limited number of authors that contribute to this volume. The result is researchers authoring two to three papers for the same geographic areas, which prevents this book from portraying a greater diversity of approaches (e.g., three individual authors contributed to eight chapters out of 21).

A particularly problematic and common theme found across some chapters is the shamanistic interpretation of the art - whereby rock paintings can be explained by the trance state experienced by shamans. Although this explanation has proven valid in the interpretations of South African and American (South and North) art, none of these contributions define the term, nor provide a proper contextualisation for the application of this framework in the study areas. Consequently, it is hard to ignore the fact that terms such as shamanism and ritual are used in some contributions as a bottomless holdall to interpret the art without providing a proper in-depth analysis of the assemblages.

Nonetheless, worth highlighting is the impressive amount of detail by some contributions in the volume that provide the reader an exhaustive outline of the work conducted, whether it be on the methods undertaken, the theoretical framework, or the combination between rock art imagery and ethnographic sources (e.g., Chapters 2, 3, 9, 10, 14, 16, 17, and 18).

In sum, this might not be a book particularly developed for those looking for a rigorous engagement with epistemological and ontological approaches to figurative motifs, nor those willing to compare rock art from different regions - due to the disparity in research represented from each area. Nevertheless, this book is a welcome addition for those scholars interested in particular independent case studies and those initiating in the study of anthropomorphic images. Despite these shortcomings, the book provides the reader with a variety of approaches that deal with the interpretation of rock art and its meanings, made possible by the inclusion of articles from across the world and ranging across different chronologies and temporalities. 